\title{
Lay Understanding of Familial Risk of Common Chronic Diseases: A Systematic Review and Synthesis of Qualitative Research
}

Fiona M. Walter, MA, MSc, FRCGP ${ }^{1}$

Jon Emery, MA, MRCGP, DPbil ${ }^{2}$

Dejana Braithwaite, $P b D^{1}$

Theresa M. Marteau, BSc, MSc, $P b D^{3}$

'General Practice \& Primary Care Research Unit, Department of Public Health \&

Primary Care, University of Cambridge, UK

${ }^{2}$ Department of General Practice, University of Western Australia, Claremont, WA

${ }^{3}$ Psychology \& Genetics Research Group, King's College, London, UK

Conflicts of interest: none

\section{CORRESPONDING AUTHOR}

Fiona M. Walter, MA, MSc, FRCGP General Practice \& Primary Care Research Unit Department of Public Health \& Primary Care Institute of Public Health

University of Cambridge

Forvie Site, Robinson Way

Cambridge CB2 2SR, UK

fmw22@medschl.cam.ac.uk

\begin{abstract}
PURPOSE Although the family history is increasingly used for genetic risk assessment of common chronic diseases in primary care, evidence suggests that lay understanding about inheritance may conflict with medical models. This study systematically reviewed and synthesized the qualitative literature exploring understanding about familial risk held by persons with a family history of cancer, coronary artery disease, and diabetes mellitus.
\end{abstract}

METHODS Twenty-two qualitative articles were found after a comprehensive literature search and were critically appraised; 11 were included. A meta-ethnographic approach was used to translate the studies across each other, synthesize the translation, and express the synthesis.

RESULTS A dynamic process emerged by which a personal sense of vulnerability included some features that mirror the medical factors used to assess risk, such as the number of affected relatives. Other features are more personal, such as experience of a relative's disease, sudden or premature death, perceived patterns of illness relating to gender or age at death, and comparisons between a person and an affected relative. The developing vulnerability is interpreted using personal mental models, including models of disease causation, inheritance, and fatalism. A person's sense of vulnerability affects how that person copes with, and attempts to control, any perceived familial risk.

CONCLUSIONS Persons with a family history of a common chronic disease develop a personal sense of vulnerability that is informed by the salience of their family history and interpreted within their personal models of disease causation and inheritance. Features that give meaning to familial risk may be perceived differently by patients and professionals. This review identifies key areas for health professionals to explore with patients that may improve the effectiveness of communication about disease risk and management.

Ann Fam Med 2004;2:583-594. DOI: 10.1370/afm.242.

\section{INTRODUCTION}

$\Lambda$ dvances in our understanding of the epidemiology of cancer, coronary artery disease, and diabetes mellitus allow the assessment of disease risk with increasing precision. Genetic factors are a component of risk for these diseases and can be assessed in clinical practice using the family history. ${ }^{1}$ The role of the family history is likely to expand from providing the traditional psychosocial insights into the context for a patient's symptoms of disease to include genetic risk assessment and management. ${ }^{2}$ Computer software exists to support risk assessment of certain cancers, ${ }^{3,4}$ coronary artery disease, ${ }^{5}$ and diabetes mellitus ${ }_{1}{ }^{6}$ but its effective use will depend on clinicians having the skills to communicate these risks in a meaningful way.

Patients' understanding about a disease, its cause, and its treatment may sometimes conflict with the medical perspective. Similarly, lay understand- 
ing of inheritance can be at variance with the biomedical model. ${ }^{7,8}$ People believe that a wide range of diseases and characteristics "run in the family." Beliefs about patterns of inheritance of physical features, character, personality, mannerisms, personal habits, health, and proneness to illness are part of family culture in Euro-American and other cultures. ${ }^{10}$ Clinicians need to be aware of these understandings, because they can influence patients' perceptions of their disease risk and its management. ${ }^{11,12}$ Effective communication about familial disease is likely to be facilitated by an appreciation of a patient's personal understanding of disease and inheritance.

The application of conventional systematic review methods to qualitative research gives rise to important philosophical and practical challenges ${ }^{13}$ when considering both the incorporation of qualitative evidence into quantitative meta-analyse ${ }^{14,15}$ and specific methods for systematic review and synthesis of qualitative research. An approach termed meta-ethnograpby has been applied to the synthesis of qualitative data in education and nursing research. ${ }^{16}$ Originally described by ethnographers working primarily with metaphors, it has recently been applied to the synthesis of qualitative data examining lay experiences of diabetes mellitus, diabetes care, and medicines. ${ }^{17,18}$ This work suggests that metaethnography is a promising method to synthesize and extend qualitative research in a defined field of study. In this review, we refined the method by conducting a systematic search strategy to select all potentially relevant articles for inclusion in the review.

We report a systematic review and synthesis of qualitative studies that explore understanding about familial risk in persons with a family history of cancer, coronary artery disease, or diabetes mellitus. We chose to focus on these conditions because they are most relevant to clinical discussions about common disease risks and involve complex gene-environment interactions. We aimed to synthesize the concepts from relevant articles to develop a theoretical framework to explain the processes by which individuals with a family history of common chronic disease develop and deal with their personal perception of disease risk.

\section{METHODS}

Our research comprised 3 distinct phases: (1) systematic literature search, (2) critical appraisal of the identified articles, and (3) subsequent meta-analysis. This meta-analysis comprised 3 stages, namely, determining the key concepts from each article, known as the firstorder constructs; translating the first-order constructs across articles to determine second-order constructs; and synthesizing these second-order constructs to produce overarching concepts, or third-order constructs.

\section{Systematic Review of the Literature}

We conducted a systematic search of the following 8 electronic databases from the year of their inception to December 2001: MEDLINE, Web of Science, PsycINFO, CancerLit, EMBASE, CINAHL, SIGLE, and Sociofile. We combined groups of terms relating to 4 specific parameters: (1) inheritance, eg, "heredity," "familial," "genetic"; (2) common chronic diseases, eg, "neoplasm," "cancer," "diabetes," "heart disease," "myocardial ischaemia"; (3) nonmedical, eg, "lay" or "patient"; and (4) understanding, eg, "beliefs," "understanding," "knowledge," "perspectives," "perceptions," "constructions," "concepts," "interpretations," "models," "meaning," and "representations."

Additional free-text searches were used for "family near history," "lay near beliefs," "commonsense," "causal," "attribution," "illness perceptions," "health near belief," and "explanatory near model." Where possible, we used the appropriate indexing term for each database. Studies were included if they used qualitative methods to examine beliefs about family history and disease risk in unaffected persons with a family history of cancer, coronary artery disease, or diabetes mellitus. No nonEnglish language articles were found during the search. We examined reference lists from all potentially relevant articles and wrote to all the first authors of articles reviewed. Titles and abstracts of articles were screened by 1 reviewer, and full-text copies of all potentially relevant articles were reviewed by at least 2 authors.

\section{Critical Appraisal of Articles}

Each article was then assessed using an existing appraisal scoring system for qualitative research (Critical Appraisal Skills Programme). ${ }^{19,20}$ Campbell's group modified the criteria by identifying the key concepts emerging from the research, and we further refined their pro forma criteria. ${ }^{18}$ Articles were independently scored, and data were extracted on a standard pro forma instrument containing 36 criteria (Table 1 ) by at least 2 authors after piloting 3 articles by consensus. Two initial screening questions were used to test against inclusion criteria: (1) Does this article report on findings from qualitative research and did that work involve both qualitative methods of data collection and data analysis? (2) Is the research relevant to the synthesis topic?

\section{Meta-analysis}

The third phase was the application of meta-ethnographic methods to analyze and synthesize the data. This involved induction and interpretation as concepts and were transferred across studies to provide synthesis We followed a 7 -step process for conducting meta-ethnography, ${ }^{16}$ incorporating Schutz's notion of first- and second-order constructs. ${ }^{21}$ 


\section{Table 1. Pro Forma Criteria for Scoring Qualitative Articles}

1. Does this article report on findings from qualitative research, and did that work involve both qualitative methods of data collection and data analysis?

\section{Is the research relevant to the synthesis topic?}

3. Aims

Is there a clear statement of the aims of the research?

\section{Methods}

Is a qualitative method appropriate?

\section{Sampling}

5.1 Is it clear where the sample was selected from?

5.2 Is it clear why this setting was chosen?

5.3 Is it clear who was selected?

5.4 Is the sample selection appropriate and justified?

5.5 Is it clear how the sample was selected?

5.6 Is the sample size justified?

5.7 Is it clear how many people accepted or refused to take part in the research?

5.8 Is it clear why some participants chose not to take part?

5.9 Is adequate information given on the characteristics of the people in the sample?

\section{Data collection}

6.1 Is it clear where the setting of the data collection was?

6.2 Is it clear why that setting was chosen?

6.3 Is it clear how the purpose of the research was explained and presented to the participants?

6.4 Is it clear how the data were collected?

6.5 Is it clear how the data were recorded?

6.6 Is it clear whether the methods were modified during the process, and if so, why?

6.7 Is it clear who collected the data?

7. Data analysis

7.1 Is it clear how the analysis was done?

7.2 Is it clear how the categories/themes were derived from the data?

7.3 Is there adequate description?

7.4 Have attempts been made to feed results back to respondents?

7.5 Have different sources of data about the same issue been compared where appropriate (triangulation)?

7.6 Was the analysis repeated by more than one researcher to ensure reliability?

\section{Research partnership relations}

8.1 Is it clear whether the researchers critically examined their own role, potential bias, and influence?

8.2 Has the relationship between researchers and participants been adequately considered?

\section{Justification of data interpretation}

9.1 Are sufficient data presented to support the descriptive findings?

9.2 Are quotes numbered/identified?

9.3 Do the researchers explain how the data presented in the article were selected from the original sample?

9.4 Do the researchers indicate links between data presented and their own interpretations of what the data contain?

9.5 Are negative, unusual, or contradictory cases presented?

9.6 Is there adequate discussion of the evidence both for and against the researchers' interpretations?

\section{Transferability}

10.1 Is there conceptual and/or theoretical congruence between this and other work?

10.2 Are the findings of this study transferable to a wider population?

11. Findings

11.1 Is it possible to summarize the findings?

11.2 Were the findings explicit and easy to understand?

Total score (of 36 criteria)
YES I NO

YES I NO

What are they?

Types/s of methods:

Inclusion and exclusion criteria:

Characteristics:

Age: Mean age: __ SD: __ Range:
Gender: Women: __ Men: ___
Subjects: Patient $\_$FDR
Other family member __ Other
Disease: Cancer

Ethnicity:

Educational level:

Socioeconomic status:

Describe setting:

Outline analysis:

$F D R=$ first-degree relative; $H D=$ heart disease 
Table 2. Grid Displaying First-Order Constructs (Key Concepts) Grouped Within Emerging Second-Order Constructs (Main Themes), by Study and Disease

\begin{tabular}{|c|c|}
\hline $\begin{array}{l}\text { Mean } \\
\text { Appraisal Score* } \\
\text { (Range) }\end{array}$ & $\begin{array}{l}\text { Diseases in } \\
\text { My Family }\end{array}$ \\
\hline \multicolumn{2}{|c|}{ Brorsson et al, 1995; hypercholesterolemia (HD) ${ }^{22}$} \\
\hline \multirow[t]{3}{*}{$19^{\dagger}$} & $\begin{array}{l}\text { "My family gets heart attacks." including } \\
\text { nongenetic family members }\end{array}$ \\
\hline & $\begin{array}{l}\text { Seriousness associated with fatal events, } \\
\text { disability, and premature deaths }\end{array}$ \\
\hline & Time lag since $\mathrm{FH}$ of event less important \\
\hline
\end{tabular}

Chalmers \& Thompson, 1996; cancer (breast) ${ }^{23}$

$23^{\dagger}$ "Walking in relative's path"

Emery et al, 1998; cancer (colorectal) (CRC) ${ }^{24}$

$26.25^{\dagger}$

Green et al, 1993; cancer (ovarian) ${ }^{25}$

18.3 (17-19) Ovarian cancer "in the family"

Relatively young age and dependent children

of affected relatives particularly upsetting

Women whose mother had died recently showed more anxiety

Few realized ovarian cancer could pass through the male line
"Living the cancer experience"

Amount of sharing of cancer experience: close attachment leads to greater shared experience

Phase and variability of illness trajectory: complicated illness leads to greater salience

Witnessing suffering: the physical and psychosocial impact
Personal Models of Disease
Understanding genetics differs from scientific explanation

"Risk framework" allows person to combine genetic and environmental risk and assess risk to offspring

Awfulness of mother's disease, rather than personal risk, especially among women whose mothers had recently died

Personal experience showed ovarian cancer likely to prove fatal if not detected early
Idiosyncratic use of genetic terms

Little understanding of genetic component of risk; also due to shared exposure to common risk factors

Models of familial disease did not follow Mendelian genetics

Harris et al,1998; CRC ${ }^{26}$

$22(21-23) \quad$ At risk if relative (not just FDR) had had CRC despite relative's age. Magnitude of family history and death of relative increase seriousness of $\mathrm{FH}$

Variable access to family history information

Hunt et al, 2000; HD $^{27}$

$25.3(23-27) \quad$ HD viewed as family condition, with perceived $\mathrm{FH}$ more than number of cardiac events in family

Relationships, ages, and pattern of death add to importance, with age at death always mentioned

Variable notion of premature death, and variable amount of $\mathrm{FH}$ information available

Effects of gender and social class

Determinants of risk: genetic predisposition, environmental risks, increasing age, other cancer, low-fiber diet, "bad luck." Concept of risk factors that trigger cancer, such as sunlight, constipation, pollution, shock

Even with several affected relatives, some thought HD due to chance. All mentioned heredity

Complex mechanism: biological and social

$\mathrm{FH}=$ family history; $\mathrm{FDR}=$ first-degree relative $\mathrm{HD}=$ heart disease; $\mathrm{DM}=$ diabetes mellitus.

* Total score $=36$.

t Pilot scores - consensus. 


\begin{tabular}{ll} 
Personalizing Risk & \multicolumn{1}{c}{$\begin{array}{c}\text { Control of } \\
\text { Familial Risk }\end{array}$} \\
\hline Perceived threat inherent in the & \\
association between hypercho- & \\
lesterolemia and the event in & \\
the FH & \\
& \\
& \\
"Developing a risk perception": & "Putting risk in its place": control- \\
comparing aspects of personal- & ling what one can; rehearsing \\
ity, lifestyle, and body type; & one's own cancer; "finding the \\
appraising own threatening & best time" as emotional control \\
experiences with breast abnor- & over risk perception; adopting \\
malities; personalizing the risk, & self-care practices \\
variable, intuitive or reasoned &
\end{tabular}

Reconstructed risk according to personal and family experiences, and personal understanding of inheritance

Dominant concept of proneness or vulnerability, especially to illness experienced by close relative of same sex

Similarities with unaffected parent could protect

Perceived personal susceptibility due to FH although there was limited

Fear and older age were barriers to screening

Distinction made between inherited risk within family as a whole and personal risk

Stressed differences from affected relatives to downplay risk

Notions of candidacy

Cardiac deaths of elderly relatives often discounted. Counter examples discussed, eg, fit young relatives "dropping dead"

No obvious controllable risk factors. Some considered removal of ovaries

Asymptomatic phase of disease

Positive about screening: "has to be better than nothing"

Peaks and troughs of anxiety, eg, before screening, approaching age of diagnosis of relative

General fear of cancer. Concern for daughters understanding

\section{First-Order Constructs}

\section{(Original Terms and Key Concepts)}

Initially, each assessor summarized the authors' original findings using original terms and key concepts from the article. These summaries were taken from the appraisal pro forma instrument and constituted the first-order constructs, which were agreed upon by consensus among all the authors.

\section{Second-Order Constructs (Translation)}

We searched for the identification concepts across each article so we could translate the first-order constructs from one study to another and determine emerging second-order constructs. Whereas Campbell's group described this translation process as a paper-based exercise, ${ }^{18}$ we attempted to increase rigor and validity by entering the first-order constructs into QSR N5 software for a qualitative analysis (Scolari, SAGE Publications Software, London, UK), which was performed by 2 authors (FMW, JE). To make this process more transparent, we completed a grid in which were placed the first-order constructs and second-order constructs from each article (Table 2). Resultant second-order constructs were agreed at a further consensus meeting.

\section{Third-Order Constructs (Synthesis)}

The second-order constructs were then used as building blocks for the line-of-argument synthesis, which interpreted relationships between them. ${ }^{16}$ Three thirdorder constructs were developed to create an overarching theoretical framework representing a further level of conceptual development incorporating all the included studies (Figure 1).

\section{RESULTS}

\section{Systematic Review}

Two hundred forty articles were reviewed at abstract level. Of the 22 articles reviewed in detail, $11 \mathrm{did}$ not meet the inclusion criteria. The principal reason for exclusion was that an article reported findings either from the general population for which family history was not recorded, or the study sample was already afflicted with the illness. Eleven articles were included in the synthesis (Table 3 ).

\section{Critical Appraisal}

The retrieved articles were heterogeneous in their clinical content, methods, and quality scores. The level of agreement on quality scoring between assessors was reasonable: agreement of 2 reviewers (FMW, JE) in coding the same criteria across 8 articles was $85 \%$ (245 of 288); in no criterion was agreement lower than $62 \%$. The 2 reviewers agreed perfectly on 12 of 36 criteria across 8 articles, and 


\begin{tabular}{|c|c|c|c|}
\hline $\begin{array}{l}\text { Mean } \\
\text { Appraisal Score* } \\
\text { (Range) }\end{array}$ & $\begin{array}{l}\text { Diseases in } \\
\text { My Family }\end{array}$ & $\begin{array}{c}\text { Experience of } \\
\text { Relative's Illness }\end{array}$ & $\begin{array}{l}\text { Personal Models } \\
\text { of Disease }\end{array}$ \\
\hline \multicolumn{4}{|c|}{ Hunt et al, 2001; HD ${ }^{28}$} \\
\hline \multirow[t]{6}{*}{$17.5(17-18)$} & $\begin{array}{l}\text { Number of affected relatives, their age, and } \\
\text { relationship }\end{array}$ & & $\begin{array}{l}\text { Genes or heredity mentioned as cause } \\
\text { by more than } 2 / 3\end{array}$ \\
\hline & $\begin{array}{l}\text { More weight given to deaths in FDRs, especially } \\
\text { parents }\end{array}$ & & $\begin{array}{l}\text { Death of one (or more) relatives could } \\
\text { be due to chance }\end{array}$ \\
\hline & Patterns of death, eg, age of death & & \\
\hline & Variable notion of premature death & & \\
\hline & $\begin{array}{l}\text { Men from manual socioeconomic groups required } \\
\text { greater number of affected relatives to perceive } \mathrm{FH}\end{array}$ & & \\
\hline & $\begin{array}{l}\text { Incomplete knowledge of } \mathrm{FH} \text { could lead to } \\
\text { ambivalence }\end{array}$ & & \\
\hline \multicolumn{4}{|c|}{ McAllister et al, 1998; cancer (breast) ${ }^{29}$} \\
\hline \multirow[t]{2}{*}{$22(22)$} & Awareness that breast cancer may be inherited & \multirow{2}{*}{$\begin{array}{l}\text { Close involvement often } \\
\text { distressing }\end{array}$} & Awareness of inheritance \\
\hline & $\begin{array}{l}\text { Variable access to family history information; } \\
\text { often avoided. Men often excluded from } \\
\text { female illness discussions }\end{array}$ & & $\begin{array}{l}\text { Multifactorial model: not attributed } \\
\text { solely to inheritance, also environmen- } \\
\text { tal risks such as smoking }\end{array}$ \\
\hline
\end{tabular}

Michie et al, 1996; cancer (colorectal: familial adenomatous polyposis) ${ }^{30}$

$25(25)$

Ryan \& Skinner, 1999; cancer (breast) ${ }^{31}$ $\begin{array}{ll}17.5(17-18) & \text { FH a risk factor, although most did not } \\ & \text { appreciate differences in risk depending } \\ & \text { on age of relative }\end{array}$
Young relatives die, undergo operations, or experience pain
Multifactorial models of genetic disease:
all mentioned genes, although uncer-
tainty about role; some aware of envi-
ronmental causes.
"Genes as a black box."
Lay models of Mendelian inheritance
Multifactorial model: lifestyle risks almost equal to familial risk; high-fiber diet or stress may be more important

Misunderstandings about risk factors: environmental toxins and drugs thought influential

Feelings of fatalism
Shepherd et al, 2000; type 2 diabetes mellitus (AODM) ${ }^{32}$

$14(13-15) \quad$ Four generations of family had 14 affected family members. DM regarded as serious disease within family
Witnessing suffering of grandfather
Causes included chutney and germs contracted while in prisoner-of-war camp. Personal models of inheritance, such as youngest child, or alternate generations. Genetic information too complicated. Mental pictures of genes

$\mathrm{FH}=$ family history; FDR = first-degree relative; $\mathrm{HD}=$ heart disease; $\mathrm{DM}=$ diabetes mellitus.

* Total score $=36$.

† Pilot scores - consensus.

only 5 criteria had agreement in fewer than 6 of the 8 articles. The intraclass correlation coefficient for total quality score was 0.84 (confidence interval, 0.41-0.97) (Table 2).

\section{Meta-analysis: First- and Second-Order Constructs}

The key concepts of each article are shown in Table 2. These first-order constructs are displayed using the original terms extracted from the articles. With the secondorder constructs (translation), 5 main interconnected themes emerged from the qualitative analysis: (1) diseases running in my family, (2) experiencing a relative's illness, (3) personal mental models, (4) personalizing vulnerability, and (5) control of familial risk (Table 2).

Diseases Running in My Family

People view particular diseases as running in their family and weigh whether a particular relative's disease contributes to this model. Certain features of a family history 


\section{Personalizing Risk \\ Distinction made between inher- ited risk within family as a whole, and personal risk \\ Stressed differences from affected relatives to downplay risk, eg, smoking, taking after other side of family. \\ Search for patterns to indicate heredity, eg, number of relatives with $\mathrm{HD}$ on one side of family}

Control of Familial Risk

Used inheritance of other characteristics, often following gender-specific pattern, to explain why not at personal risk

(Potential) daughters at higher risk because of $\mathrm{FH}$; no concerns about (potential) son's health

Proneness, vulnerability not a problem colluded with
Often highly ambivalent about FH

Many continue wrestling with decisions about modifying behavior especially weight and effects of age
Continuing anxiety, especially about own and daughter's risk

Avoidance of, or exclusion from, discussions about breast cancer

"Girl's problem," which most men

Some: "there is no problem"

Screening seen as aversive, but important: "a necessary evil," "seeing is believing"

Vagueness about genetic testing: little evidence of informed decision making

Uncertainty of not being diagnosed

"Functional pessimism" to cope

Screening could cause cancer Wanted thorough analysis of risk, then recommendations for lowering risk. Fewer than one half wanted to know genetic susceptibility status: many concerns. Risk modification by lifestyle changes welcomed

Physical resemblance of family members linked to those thought likely to develop DM
Figure 1. Third-order constructs and their interrelationships: a theoretical framework of how persons with familial risk develop and manage their personal sense of vulnerability.

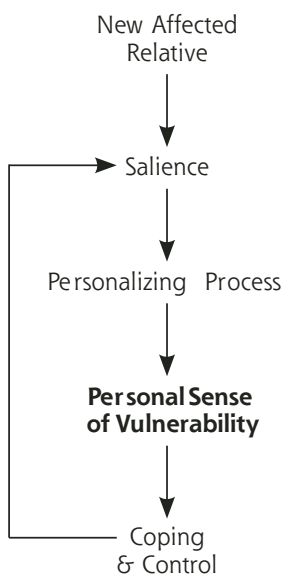

the familial events is less important. There is sometimes ambivalence and uncertainty about whether a disease does run in the family, which may be exacerbated by difficulty obtaining accurate information about the family history. Perceptions vary across sex and class. For example, because of the high occurrence of sudden or premature cardiac death in the wider social context, workingclass men needed more examples than middle-class men of deaths caused by heart disease in their family before perceiving themselves as having a familial risk. ${ }^{28}$

\section{Experiencing a Relative's Illness}

Perceptions of disease risk are influenced by an individual's personal experience of a relative's illness. Witnessing suffering describes the extent to which the physical and psychosocial impact of the relative's illness is observed, and it is influenced further by the emotional closeness between the individual and his or her affected relative. The more complex and variable the illness trajectory, the greater the lived experience, and hence the greater the perceived importance of the family history. These issues were discussed in only 5 articles ${ }^{23,25,29,30,32}$ but were implicit in others. ${ }^{24,31}$

\section{Personal Mental Models}

Individuals hold personal mental models of health, disease causation, and inheritance that often contrast with scientific concepts. For example, even among persons at high risk of carrying highly penetrant mutations in the APC gene (mutated in persons with familial adenomatous polyposis), BRCA1/2 gene (mutated in persons with breast cancer) or MODY gene (mutated in persons with maturity-onset diabetes of the young), few perceived inheritance as a sole cause of specific cancers, coronary artery disease, or diabetes mellitus. Familial risk was per- 
ceived as multifactorial, reflecting shared environmental and behavioral, as well as inherited, factors.

Mental models of inheritance were also frequently described. Individuals often hold personal constructs of genes, DNA, and chromosomes, which they use to understand the process of inheritance. Two articles described how respondents believed it was unnecessary to understand genetic principles, only their consequences in terms of how to manage personal risk and the risk to future generations. ${ }^{24,32}$

Models of disease causation also incorporated notions of bad luck, chance, and fate. Although some believed they could reduce their chances of an event that was determined largely by bad luck, others felt deeply fatalistic about familial risk of disease, particularly diseases that have symptoms late in their development, such as ovarian or colorectal cancer or sudden death caused by coronary artery disease.

\section{Personalizing Vulnerability}

Individuals with a family history of a common chronic disease develop a sense of vulnerability through a fluid and dynamic process in which they continue to weigh the importance of ongoing events in their family. This risk processing includes counting and discounting certain familial events, such as whether deaths could be attributed to old age rather than to a particular disease. Counterexamples, such as fit relatives dropping dead or relatives with multiple risk factors living to an old age, are used to reduce the perceived importance of a family history of disease. Comparisons between their own and affected relatives' personality, physical characteristics, or lifestyle are commonly made when considering their familial risk. Some interpret similarities as increasing their risk, while others downplay their family history by stressing differences between themselves and their affected relatives. Additional patterns within a family history are considered, such as specific ages at diagnosis against which further personal comparisons are made. This personalizing of risk information allows individuals to evaluate whether they themselves or other members of the family are more or less vulnerable to a specific disease.

\section{Control of Familial Risk}

Among those who acknowledge personal susceptibility, attempts are made, with varying degrees of success, to control or reduce vulnerability by changing behavior or undergoing disease screening. Establishing risk management behaviors was seen to be a complex, multifaceted process that can promote a sense of personal control and predictability, allowing people to continue their lives in the face of disease risk. In some studies some individuals actively sought screening, even when their familial risk was believed to be low or there were uncer- tainties about the scientific evidence to support specific screening tests. Gaining actual control of familial risk is not always achieved, however, given continued uncertainties about the value of screening and behavior changes. Perceptions varied across diseases: heart disease and diabetes were perceived by some as less threatening or "a good way to go" and therefore more acceptable as a mode of death or disability, whereas ovarian or colorectal cancer were perceived as more threatening, in part because they have few controllable lifestyle risk factors or early warning symptoms.

\section{Meta-analysis: Third-Order Constructs (Synthesis)}

The second-order constructs all contribute toward how people make sense of their family history. We therefore conducted a line-of-argument synthesis seeking to reveal what may not be overt in individual studies to elucidate overarching concepts. ${ }^{16}$ Our synthesis aimed to develop a model to explain the overall processes by which people make sense of their family history. Three main third-order constructs resulted from our synthesis, namely: (1) salience, (2) personalizing processes, and (3) personal sense of vulnerability.

The salience of a family history, determined by the acknowledgment that a disease runs in the family, is strongly influenced by the personal experiences of that illness. It describes a number of factors that would, either singly or more commonly in combination, cause a person to believe a disease may run in the family and, therefore, cause that person to be at increased risk of this disease. Some factors mirror medical factors used to assess risk (such as the number of affected relatives), but others may be more personal, such as the influence of emotional or physical closeness to an affected relative and the specific experiences of the disease in the family.

Personal mental models of health and disease inheritance and disease causation are applied to make sense of the salient features of the family history and inform the personalizing process. These models may vary within and between individuals, groups, and societies. In particular, they may conflict with accepted scientific models, particularly in the way people view disease causation, health and illness, and inheritance.

A resultant personal sense of vulnerability emerges as the core third-order construct and describes the outcome of processing the salient features of the family history into a sense of personal, individual risk, which can be applied to the self and other family members. Just as the personalizing process is fluid, the sense of vulnerability also changes according to the influence of both salience and personal mental models. In turn, a person's sense of vulnerability affects how that person copes with and attempts to control familial risk.

Figure 1 displays the close interrelationships between 


\begin{tabular}{|c|c|c|c|c|c|}
\hline Disease & Location & Setting & $\begin{array}{l}\text { Sample } \\
\text { No. and Sex }\end{array}$ & $\begin{array}{l}\text { Age Range } \\
\text { Years }\end{array}$ & $\begin{array}{l}\text { Study } \\
\text { Methods }\end{array}$ \\
\hline \multicolumn{6}{|l|}{ Brorsson et al, $1995^{22}$} \\
\hline $\begin{array}{l}\text { Hypercholesterolemia } \\
\text { (HD) }\end{array}$ & Malmo, Sweden & $\begin{array}{l}\text { Health Survey Study at Primary Health Care } \\
\text { Centre: men with moderately elevated } \\
\text { cholesterol levels }\end{array}$ & 63 men & $35-45$ & Interview \\
\hline \multicolumn{6}{|c|}{ Chalmers \& Thompson, $1996^{23}$} \\
\hline Cancer (breast) & Winnipeg, Canada & $\begin{array}{l}\text { FDRs of women with breast cancer: multiple } \\
\text { recruitment strategies }\end{array}$ & 55 women & $\begin{array}{l}18 \leq 50 \\
37 \leq 50\end{array}$ & Interview \\
\hline \multicolumn{6}{|l|}{ Emery et al, $1998^{24}$} \\
\hline Cancer (colorectal) & Wessex, UK & Referrals to family cancer genetics clinic & $\begin{array}{l}11 \text { women } \\
6 \text { men }\end{array}$ & $\begin{array}{c}28-86 \\
\text { mean } 52\end{array}$ & Interview \\
\hline \multicolumn{6}{|l|}{ Green et al, $1993^{25}$} \\
\hline Cancer (ovarian) & Cambridge, UK & $\begin{array}{l}\text { Self-referrals to UKCCCR Familial Ovarian } \\
\text { Cancer Register }\end{array}$ & 20 women & $\begin{array}{l}33-72 \\
\text { (most in } 40 \text { s) }\end{array}$ & Interview \\
\hline \multicolumn{6}{|l|}{ Harris et al, $1998^{26}$} \\
\hline Cancer (colorectal) & $\begin{array}{l}\text { Newcastle, NSW, } \\
\text { Australia }\end{array}$ & $\begin{array}{l}\text { Random sample (at least } 1 \text { affected FDR) from } \\
\text { surveillance file of colorectal surgeon }\end{array}$ & $\begin{array}{l}12 \text { women } \\
12 \text { men }\end{array}$ & $\begin{array}{l}40-70 \\
\text { mean } 50\end{array}$ & $\begin{array}{l}4 \text { focus } \\
\text { groups }\end{array}$ \\
\hline \multicolumn{6}{|l|}{ Hunt et al, $2000^{27}$} \\
\hline HD & West Scotland, UK & $\begin{array}{l}\text { Purposively sampled health study respondents } \\
\text { (FASTCARD) }\end{array}$ & $\begin{array}{l}31 \text { women } \\
30 \text { men }\end{array}$ & $41-51$ & Interview \\
\hline \multicolumn{6}{|l|}{ Hunt et al, $2001^{28}$} \\
\hline $\mathrm{HD}$ & West Scotland, UK & $\begin{array}{l}\text { Purposively sampled health study respondents } \\
\text { (FASTCARD) }\end{array}$ & $\begin{array}{l}31 \text { women } \\
30 \text { men }\end{array}$ & $41-51$ & Interview \\
\hline \multicolumn{6}{|c|}{ McAllister et al, $1998^{29}$} \\
\hline Cancer (breast) & Dublin, Ireland, UK & $\begin{array}{l}\text { Men with at least } 1 \text { affected FDR identified } \\
\text { from oncology clinic }\end{array}$ & 22 men & $25-60$ & Interview \\
\hline \multicolumn{6}{|l|}{ Michie et al, $1996^{30}$} \\
\hline $\begin{array}{l}\text { Cancer (colorectal, } \\
\text { FAP) }\end{array}$ & London, UK & From Polyposis Register of specialist hospital & $\begin{array}{l}12 \text { women } \\
8 \text { men }\end{array}$ & $\begin{array}{c}15-46 \\
\text { mean } 27\end{array}$ & Interview \\
\hline \multicolumn{6}{|c|}{ Ryan \& Skinner $1999^{31}$} \\
\hline Cancer (breast) & Missouri, USA & FDRs of recent patients at oncology clinic & 29 women & $\begin{array}{l}22-65 \\
\text { mean } 40\end{array}$ & $\begin{array}{l}4 \text { focus } \\
\text { groups }\end{array}$ \\
\hline \multicolumn{6}{|c|}{ Shepherd et al, $2000^{32}$} \\
\hline Diabetes (MODY) & Exeter, UK & $\begin{array}{l}\text { MODY-affected family and health } \\
\text { professionals from secondary care }\end{array}$ & $\mathrm{n} / \mathrm{a}$ & $\mathrm{n} / \mathrm{a}$ & Case study \\
\hline
\end{tabular}

IHD = hypercholesterolemia; FDR = first-degree relative; UKCCCR = United Kingdom Coordinating Committee on Cancer Research; FAP = familial adenomatous polyposis; MODY $=$ maturity-onset diabetes of the young; $\mathrm{n} / \mathrm{a}=$ not available; $\mathrm{HD}=$ heart disease.

the third-order constructs, and offers a theoretical framework that describes the way people develop and manage their personal sense of vulnerability. This framework encompasses all the studies included in the review and represents a further level of development by presenting a conceptual model by which people make sense of and deal with their family history of disease. The development of a personal sense of vulnerability is not a linear process; rather it is an intermittent, dynamic process based on continuing interpretation and evaluation of new experiences. When a relative has a specific disease, family members develop a personal sense of vulnerability that is informed by the salience of their family history and interpreted within their personal models of disease causation and inheritance. They then attempt to minimize the threats they face to avoid feeling emotionally overwhelmed and gain control over their personal vulnerability, for example through screening and behavior change.

\section{DISCUSSION}

This study used the 3 -staged approach of a rigorous literature search, critical appraisal, and meta-ethnography to review and synthesize qualitative research in a systematic manner. We identified major issues about the use of family history in clinical care, lay and professional differences in understanding inheritance, and how the acknowledgment of these differences could be applied to improve communication regarding familial disease risk and its management.

This synthesis illustrates features of the family history that may be perceived differently by patients and clinicians and thereby affect perceptions of disease risk. Clinicians already acknowledge the potential benefit of applying information about family history in chronic disease prevention. ${ }^{33}$ Yet whereas clinicians currently ask about the number of affected relatives and their age at illness and death, patients' perceptions of the impor- 
tance of their family history also reflect their personal experience of the disease, including premature death or disability and perceived patterns of illness relating to gender or age at death. Beliefs have been shown to vary across gender, class, and disease and would also be expected to show cultural and ethnic diversity, ${ }^{34,35}$ although the articles included in this review examined beliefs predominantly in white Euro-American subjects The number of articles in the synthesis was insufficient to adequately compare perceptions across diseases. While familial risk of some cancers was viewed with uncertainty or dread, familial risk of heart disease evoked less concern. Indeed, sudden cardiac death was viewed as a "good way to go" by some. Diabetes is also perceived as less threatening and is seen as more similar to heart disease than cancer. ${ }^{36}$ Thus, the different threat evoked by each disease may alter an individual's sense of personal vulnerability to that disease.

The crucial questions for an individual with a family history of a common chronic disease are, "Is this disease running in my family?" "How does this affect my own likelihood of developing it?" "Can I change my disease risk by changing my diet or behavior or by taking medication?" Acknowledging that one has a family history encompasses understanding not only the influence of genes shared with affected relatives but also the influence of shared environment. When assessing the personal relevance of the family history, comparisons are made between one's own attributes and those of affected relatives. This finding is consistent with previous research that people view disease risk as closely linked to inheritance of discrete physical characteristics, personality, and behavior. ${ }^{10,37}$

The features that determine salience of a family history for an individual include some of the traditional factors used by health professionals to assess risk. Additional features, however, such as emotional closeness and experiences of a relative's illness, further determine an individual's risk perception. This finding highlights a potential mismatch in the way lay and professional populations understand familial disease. People may wish only to manage their personal disease risk and understand the risk to future generations rather than to understand the underlying scientific explanation. ${ }^{38}$ Conflicts between lay and scientific models of inheritance could result in persistent misconceptions and fears concerning familial risk. Richards suggested that health professionals must understand patient's beliefs about inheritance to make genetic counseling useful, 39,40 and this caveat may also apply in primary care, where concerns about family history are initially discussed.

A personal sense of vulnerability was identified in this review as an outcome of the dynamic process of personalizing risk. This finding supports previous work showing that a perceived family history of heart disease is strongly associated with an individual's perceived vulnerability to heart disease. ${ }^{41}$ The concept of vulnerability has been discussed in the context of coronary candidacy, or "the sort of person who gets heart trouble." 42 Candidacy is judged by physical appearance, the existence of heart trouble in close relatives, and personal observation of the candidate's nature and behavior, while acknowledging that luck or fate plays an important role in determining who develops a particular disease. ${ }^{43}$ This review suggests that the concept of disease candidacy may extend to other diseases such as cancer.

\section{Strengths and Limitations}

We extended previous approaches to systematic review of qualitative research ${ }^{17,18}$ by using systematic search strategies to identify all potentially relevant articles. We conducted electronic searches of 8 databases of the biomedical and social science literature using a search strategy that embraced the multiplicity of terms to describe lay beliefs. It is likely that we identified most relevant studies. The meta-ethnographic approach assumes that concepts within an individual article are transferable and can be used as a primary source of data. We believe that the congruence of concepts across articles supports this viewpoint. Disagreements between articles, such as the fatalism associated with a family history of cancer compared with a family history of coronary artery disease or diabetes mellitus can be viewed as contradictory cases within a standard qualitative analysis and used to clarify emerging themes. Further support for our synthesis could come from validation of the third-order constructs by consultation with the authors of the original articles. Most articles in this review described participants recruited from family history clinics in secondary care. Further validation of this synthesis is required by exploring beliefs held by persons with a family history of disease recruited from other settings.

Lay understanding of familial risk of disease has been infrequently studied. Most research is based on qualitative studies and a few surveys. ${ }^{36,44}$ Although there have been many articles showing that risk perception varies according to family history, we found only 11 articles that explored how those with a family history of a common illness make sense of their family history. Most accounts related to a family history of cancer ${ }^{23-26,29-31}$; only 1 article related to a family history of diabetes mellitus. ${ }^{32}$ Among these 11 articles, only 2 were concerned with a dominantly inherited disease (familial adenomatous polyposis) ${ }^{30}$ and maturity-onset diabetes of the young, ${ }^{32}$ whereas most studies examined the patients with a family history of complex diseases. 


\section{Implications for Future Research and Practice}

Meta-ethnography is a valuable method for the synthesis of qualitative literature and could be applicable for research in primary care and other disciplines. When discussing familial risk of disease with patients in a clinical setting, it is important to explore the features identified in this review, such as patients' experiences of a relative's illness and personal models of disease causation (Table 4 ). Health professionals and patients alike may perceive the family history as due to shared environmental risk factors as well as shared genes. ${ }^{45}$ It has been argued that if a disease is thought to be caused solely by genetics, people may develop notions of fatalism and not alter their health-related behaviors. ${ }^{38}$ This review suggests that the common multifactorial model of familial risk may enable people to change their behavior and exert some form of control over their perceived vulnerability. Differing senses of vulnerability to different diseases will influence the way people respond when health professionals discuss disease risk, particularly when lay and professional models of vulnerability differ. By exploring the patient's underlying beliefs identified in this review, the health professional can discuss management of disease risk in a manner that is consistent with the patient's individual sense of vulnerability. By exploring their patients' understanding, clinicians can develop a greater understanding of what impedes and what facilitates behavior change, as well as what affects vulnerability, coping, and control. Gaining knowledge of the patient's perspective builds on traditional models of physicianpatient communication, ${ }^{46}$ giving greater clarity to the range of lay understandings that should be explored as a component of effective risk communication.

\section{CONCLUSION}

Family history will increasingly be used as a marker of genetic risk to identify populations and individuals at increased risk who may benefit most from screening, behavior change, and chemoprevention strategies. Equally, there will be a role to play in reassuring patients when their family history does not greatly affect their disease risk. ${ }^{47}$ Effective communication of such risk information will require health professionals to explore patients' understanding about inheritance and what underlies their sense of vulnerability. ${ }^{48}$ This review identifies key areas to explore with patients that may influence the effectiveness of both risk communication and disease management strategies.

To read or post commentaries in response to this article, see it online at http://www.annfammed.org/cgi/content/full/2/6/583.

Submitted September 17, 2003; submitted, revised, March 12, 2004; accepted March 17, 2004

Key words: Heredity; risk factors/genetics; health behavior; beliefs; internalexternal control; review literature; cancer; coronary disease; diabetes mellitus

A version of this article was given as an oral presentation at the British Society of Human Genetics, Cancer Genetics Group, May 2003; as a poster presentation at the Society for Academic Primary Care Annual Science Meeting, July 2003; and as a poster presentation at the American Society of Human Genetics 53rd Annual Meeting, November 2003.

Acknowledgments: Fiona Walter was funded by a NHS RED Health Service Research Fellowship, Jon Emery and Dejana Braithwaite by Cancer Research UK, and Theresa Marteau by The Wellcome Trust. The authors would like to acknowledge and thank Professors Nicky Britten, Ann Louise Kinmonth, Martin Richards, Ann Robertson, and Mrs. Hilarie Bateman for their insightful comments on earlier drafts of this manuscript.

\section{References}

1. Yoon PW, Scheuner MT, Peterson-Oehlke KL, et al. Can family history be used as a tool for public health and preventive medicine? Genet Med. 2002;4:304-310.

2. Emery J, Rose P. Expanding the role of the family history in primary care. Br J Gen Pract. 1999;49:260-261.

3. Emery J, Walton R, Coulson A, et al. Computer support for recording and interpreting family histories of breast and ovarian cancer in primary care (RAGs): qualitative evaluation with simulated patients. BMJ. 1999;319:32-36. 
4. Emery J, Walton R, Murphy M, et al. Computer support for interpreting family histories of breast and ovarian cancer in primary care: comparative study with simulated cases. BMJ. 2000;321:28-32.

5. Montgomery AA, Fahey T, Peters TJ, et al. Evaluation of computer based clinical decision support system and risk chart for management of hypertension in primary care: randomised controlled trial. $B M J$. 2000;320:686-690.

6. Griffin SJ, Little PS, Hales CN, et al. Diabetes risk score: towards earlier detection of type 2 diabetes in general practice. Diabetes Metab Res Rev. 2000;16:164-171.

7. Marteau TM, Richards MPM, eds. The Troubled Helix: Social and Psychological Implications of the New Human Genetics. Cambridge: Cambridge University Press; 1996.

8. Cox S, McKellin W. 'There's this thing in our family': predictive testing and the construction of risk for Huntington disease. Sociol Health Illn. 1999;21:622-646

9. Richards MPM. Families, kinship and genetics. In: Marteau TM, Richards MPM, eds. The Troubled Helix: Social and Psychological Implications of the New Human Genetics. Cambridge: Cambridge University Press; 1996:249-273.

10. Davison C. Predictive genetics: the cultural implications of supplying probable futures. In: Marteau TM, Richards MPM, eds. The Troubled Helix: Social and Psychological Implications of the New Human Genetics. Cambridge: Cambridge University Press; 1996:317-330.

11. Dines A. A review of lay beliefs research: insights for nursing practice in health promotion. J Clin Nurs. 1994;3:329-338.

12. Bottorff JL, Ratner PA, Johnson JL, et al. Communicating cancer risk information: the challenges of uncertainty. Patient Educ Couns. 1998;33:67-81.

13. Murphy E, Dingwall R, Greatbatch Parker S, Watson P. Qualitative research methods in health technology assessment: a review of the literature. Health Technol Assess. 1998;2:iii-ix;1-274.

14. Dixon-Woods M, Fitzpatrick R. Qualitative research in systematic reviews has established a place for itself. BMJ. 2001;323:765-766.

15. Centre for Reviews and Dissemination. Undertaking Systematic Reviews of Research on Effectiveness. 2nd ed. York, UK: NHS Centre for Reviews and Dissemination; 2001. Available at: http://www. york.ac.uk/inst/crd/report4.htm.

16. Noblit GW, Hare RD. Meta-Ethnography: Synthesizing Qualitative Studies. London: Sage Publications; 1988.

17. Britten N, Campbell R, Pope C, et al. Using meta-ethnography to synthesise qualitative research: a worked example. J Health Serv Res Policy. 2002;7:209-215.

18. Campbell R, Pound P, Pope C, et al. Evaluating meta-ethnography: a synthesis of qualitative research on lay experiences of diabetes and diabetes care. Soc Sci Med. 2003;56:671-684.

19. Learning and Development, Public Health Resource Unit. Critical Appraisal Skills Programme (CASP). 1998. Available at: http://www. phru.nhs.uk/casp/casp.htm.

20. Giacomini MK, Cook DJ. Users' guides to the medical literature: XXIII. Qualitative research in health care B. What are the results and how do they help me care for my patients? Evidence-Based Medicine Working Group. JAMA. 2000;284:478-482.

21. Schutz A. Collected Papers. Vol 1: The Problem of Social Reality. The Hague: Martinus Nijhoff; 1962.

22. Brorsson $A$, Troein $M$, Lindbladh $E$, et al. My family dies from heart attacks. How hypercholesterolaemic men refer to their family history. Fam Pract. 1995;12:433-437.

23. Chalmers K, Thomson K. Coming to terms with the risk of breast cancer: perceptions of women with primary relatives with breast cancer. Qual Health Res. 1996;6:256-282.

24. Emery J, Kumar S, Smith H. Patient understanding of genetic principles and their expectations of genetic services within the NHS: a qualitative study. Community Genet. 1998;1:78-83.

25. Green J, Murton F, Statham H. Psychosocial issues raised by a familial ovarian cancer register. J Med Genet. 1993;30:575-579.
26. Harris MA, Treloar C, Byles JE. Colorectal cancer screening: discussions with first degree relatives. Aust NZ J Public Health. 1998;22:826-828.

27. Hunt K, Emslie C, Watt G. Barriers rooted in biography: how interpretation of family patterns of heart disease and early life experiences may undermine behavioural change in mid-life. In: Graham H, ed. Understanding Health Inequalities. Buckingham: Open University Press; 2000:113-126.

28. Hunt K, Emslie C, Watt G. Lay constructions of a family history of heart disease: potential for misunderstandings in the clinical encounter? Lancet. 2001; 357:1168-1171.

29. McAllister MF. Men in breast cancer families: a preliminary qualitative study of awareness and experience. J Med Genet. 1998;35:739744.

30. Michie S, McDonald V, Marteau TM. Understanding responses to predictive genetic testing: a grounded theory approach. Psychol Health. 1996;11:455-470

31. Ryan EL, Skinner CS. Risk beliefs and interest in counseling: focusgroup interviews among first-degree relatives of breast cancer patients. J Cancer Educ. 1999;14:99-103.

32. Shepherd M, Sparkes AC, Hattersley AT. Lay beliefs about maturityonset diabetes of the young. J Diabet Nurs. 2000;4:140-143.

33. Fry A, Campbell H, Gudmunsdottir H, et al. GPs' views on their role in cancer genetics services and current practice. Fam Pract. 1999; 16:468-474.

34. Sensky T. Eliciting lay beliefs across cultures: principles and methodology. Br J Cancer Suppl. 1996;29:S63-S65.

35. Pfeffer N, Moynihan C. Ethnicity and health beliefs with respect to cancer: a critical review of methodology. Br J Cancer Suppl. 1996;29:S66-S72.

36. Pierce M, Harding D, Ridout D, et al. Risk and prevention of type II diabetes: offspring's views. Br J Gen Pract. 2001;51:194-199.

37. Davison C, Frankel S, Smith DG. Inheriting heart trouble: the relevance of common-sense ideas to preventive measures. Health Educ Res. 1989;4:329-340.

38. Senior V, Marteau TM, Peters TJ. Will genetic testing for predisposition for disease result in fatalism? A qualitative study of parent's responses to neonatal screening for familial hypercholesterolaemia. Soc Sci Med. 1999:48:1857-1860.

39. Richards MPM. The new genetics: some issues for social scientists. Sociol Health Illn. 1993;15:567-686.

40. Richards MPM. Lay and professional knowledge of genetics and inheritance. Pub Understand Sci. 1996;5:217-230.

41. Hunt K, Davison C, Emslie C, Ford G. Are perceptions of a family history of heart disease related to health- related attitudes and behaviour? Health Educ Res. 2000;15:131-143.

42. Frankel S, Davison C, Davey Smith G. Lay epidemiology and the rationality of responses to health education. $\mathrm{Br} J \mathrm{Gen}$ Pract. 1991;41:428-430.

43. Davison C, Frankel S, Davey Smith G. The limits of lifestyle: reassessing 'fatalism' in the popular culture of illness prevention. Soc Sci Med. 1992;34:675-685.

44. Watt G, McConnachie A, Upton M, et al. How accurately do adult sons and daughters report and perceive parental deaths from coronary disease? J Epidemiol Community Health. 2000;54:859-563.

45. Kumar S, Gantley M. Tensions between policy makers and general practitioners in implementing new genetics: grounded theory interview study. Brit Med J. 1999;319:1410-1413.

46. Pendleton D, Schofield T, Tate P. The Consultation: An Approach to Learning and Teaching. Oxford: Oxford University Press; 1984.

47. Grande GE, Hyland F, Walter FM, Kinmonth AL. Women's views of consultations about familial risk of breast cancer in primary care. Patient Educ Couns. 2002;48:275-282.

48. Stewart MA, Brown JB, Weston WWW et al. Patient-Centred Medicine: Transforming the Clinical Method. Newbury Park, Calif: Sage Publications; 1995. 